\title{
BMJ Global Health Facial protection for healthcare workers during pandemics: a scoping review
}

\author{
Laura R Garcia Godoy (D) ,' Amy E Jones \\ Cameron L Fisher (D) , ${ }^{1}$ Kylie M L Seeley \\ Hannah K Zane (D) , ' Jaime W Peterson
}

To cite: Garcia Godoy LR, Jones AE, Anderson TN, et al. Facial protection for healthcare workers during pandemics: a scoping review. BMJ Global Health 2020;5:e002553. doi:10.1136/ bmjgh-2020-002553

Handling editor Soumyadeep Bhaumik

- Additional material is published online only. To view please visit the journal online (http://dx.doi.org/10.1136/ bmjgh-2020-002553).

LRGG and AEJ contributed equally.

LRGG and AEJ are joint first authors.

Received 31 March 2020 Revised 22 April 2020 Accepted 23 April 2020

\section{Check for updates}

(C) Author(s) (or their employer(s)) 2020. Re-use permitted under CC BY-NC. No commercial re-use. See rights and permissions. Published by BMJ.

${ }^{1}$ School of Medicine, Oregon Health and Science University, Portland, Oregon, USA

${ }^{2}$ Department of Pediatrics, Oregon Health and Science University Hospital, Portland, Oregon, USA

${ }^{3}$ Department of Internal Medicine, Oregon Health and Science University Hospital, Portland, Oregon, USA

Correspondence to Ms Amy E Jones; jonesamy@ohsu.edu

\section{ABSTRACT}

Background The coronavirus disease 2019 (COVID-19) pandemic has led to personal protective equipment (PPE) shortages, requiring mask reuse or improvisation. We provide a review of medical-grade facial protection (surgical masks, N95 respirators and face shields) for healthcare workers, the safety and efficacy of decontamination methods, and the utility of alternative strategies in emergency shortages or resource-scarce settings.

Methods We conducted a scoping review of PubMed and grey literature related to facial protection and potential adaptation strategies in the setting of PPE shortages (January 2000 to March 2020). Limitations included few COVID-19-specific studies and exclusion of non-English language articles. We conducted a narrative synthesis of the evidence based on relevant healthcare settings to increase practical utility in decision-making.

Results We retrieved 5462 peer-reviewed articles and 41 grey literature records. In total, we included 67 records which met inclusion criteria. Compared with surgical masks, N95 respirators perform better in laboratory testing, may provide superior protection in inpatient settings and perform equivalently in outpatient settings. Surgical mask and N95 respirator conservation strategies include extended use, reuse or decontamination, but these strategies may result in inferior protection. Limited evidence suggests that reused and improvised masks should be used when medical-grade protection is unavailable.

Conclusion The COVID-19 pandemic has led to critical shortages of medical-grade PPE. Alternative forms of facial protection offer inferior protection. More robust evidence is required on different types of medical-grade facial protection. As research on COVID-19 advances, investigators should continue to examine the impact on alternatives of medical-grade facial protection.

\section{INTRODUCTION}

On 31 December 2019, the Wuhan Municipal Health Commission announced an outbreak of a novel coronavirus, severe acute respiratory syndrome coronavirus 2 (SARS-CoV-2). Within 3 months of initial reporting of this novel coronavirus, cases had surpassed 100000 worldwide, and less than 2 weeks later,

\section{Key questions}

What is already known?

- Current WHO practice guidelines for preventing respiratory transmission of severe acute respiratory syndrome coronavirus 2 (SARS-CoV-2) include the use of N95 respirators for aerosol-generating procedures and surgical masks in other patient contac settings.

\section{What are the new findings?}

- Compared with surgical masks, N95 respirators perform better in laboratory testing, may provide superior protection in inpatient settings and are equivalent in outpatient settings; conservation strategies result in inferior protection but include extended use reuse, decontamination of medical-grade masks or the use of improvised cloth masks, both of which may be combined with a face shield.

- Limitations of this scoping review include the relative scarcity of COVID-19-specific studies and exclusion of non-English language articles.

What do the new findings imply?

- There is not much evidence on conservation strategies that could help conserve personal protective equipment during emergency shortages.

- Further research regarding the safety and efficacy of these practices is required in order to establish evidence-based guidelines for healthcare workers.

global cases had doubled. ${ }^{1}$ This pandemic has put immense strain on medical systems, leading to current or impending shortages of personal protective equipment (PPE). On 7 February 2020, the WHO estimated that demand for PPE had increased by 100-fold since the start of the outbreak, with prices increasing up to 20-fold. ${ }^{2}$ Prices continued to surge throughout the month of March 2020, and the New York Times reported that the federal stockpile for public health emergencies can only meet approximately $1 \%$ of the estimated need. ${ }^{3}$ As a result of the high medical demand and system strain caused by SARS-CoV-2, efforts to produce and stockpile 
Table 1 Types of medical-grade facial protection

\begin{tabular}{|c|c|}
\hline Mask types & Function \\
\hline or & $\begin{array}{l}\text { A respiratory protective device designed to achieve a close facial fit and efficient filtration of airborne particles, } \\
\text { requires fit testing to be fully effective. }{ }^{67} \\
\text { Prevents inhalation of } 95 \% \text { of } 0.3 \mu \text { m particles. } \\
\text { - Reduces person-to-person transfer of respiratory droplets. } \\
\text { Blocks blood and bodily fluids from reaching the wearer's mouth and nose. } \\
\text { Prevents inhalation of droplets and larger particles. } \\
\text { Filtration of all air reaching the mouth and nose is required for particles } \geq 5 \mu \mathrm{m} \text {. } \\
\text { Surgical N95 respirators are used in healthcare settings and are a subset of N95 filtering facepiece } \\
\text { respirators. }\end{array}$ \\
\hline Surgi & $\begin{array}{l}\text { A loose-fitting, disposable device that creates a physical barrier between the mouth and nose of the wearer } \\
\text { and potential contaminants in the immediate environment. } \\
\text { - Reduces person-to-person transfer of respiratory droplets. } \\
\text { - Blocks blood and bodily fluids from reaching the wearer's mouth and nose. } \\
\text { - Prevents inhalation of droplets and larger particles. } \\
\text { Filtration of all air reaching the mouth and nose is required for particles } \geq 5 \mu \mathrm{m} \text {. }\end{array}$ \\
\hline Face shield & $\begin{array}{l}\text { A face shield provides barrier protection to the facial area and related mucous membranes (eyes, nose, lips). }{ }^{19} \\
\text { Current Healthcare Infection Control Practices Advisory Committee (HICPAC) guidelines explicitly } \\
\text { recommend wearing a face shield or goggles during all patient care for certain illnesses such as severe } \\
\text { acute respiratory syndrome (SARS) and avian influenza. }{ }^{68}\end{array}$ \\
\hline
\end{tabular}

a sufficient supply of N95 respirators and face masks have fallen short.

The type and amount of PPE that should be used when treating a patient with coronavirus disease 2019 (COVID19) varies based on clinical job and setting. ${ }^{4}$ For healthcare workers providing direct inpatient care for patients with COVID-19, a medical mask, gown, gloves and eye protection in the form of goggles or a face shield should be used. ${ }^{4}$ If aerosol-generating procedures are being performed, healthcare workers should also wear an apron and use an N95 respirator in the place of a surgical mask. ${ }^{4}$ In outpatient settings, providers examining patients with respiratory symptoms should wear a medical mask, gown, gloves and eye protection. ${ }^{4}$ A different set of PPE requirements for healthcare workers not involved in direct care of patients with COVID-19 and for the general public have been outlined by the WHO and vary based on circumstance. If medical-grade PPE is not available or in short supply, the WHO recommends appropriate and minimised use of PPE according to clinical setting and personnel. ${ }^{4}$

The purpose of this scoping review is to compile existing evidence on the use and efficacy of medical-grade and alternative forms of facial protection for healthcare workers amidst the growing global shortage. For the purposes of this review, 'facial protection' refers to surgical masks, N95 respirators and face shields (table 1). In studies that did not specify the category of protection, the term 'PPE' is used.

\section{METHODS}

We conducted a scoping review and present our findings in accordance with the Preferred Reporting Items for Systematic Reviews and Meta-Analysis Extension for Scoping Reviews reporting standards. ${ }^{5}$ A scoping review was most appropriate due to the broad nature of this subject and range of potential adaptation strategies in the setting of a medical-grade mask shortage secondary to the COVID-19 pandemic. Furthermore, due to the recent emergence of SARS-CoV-2, it was necessary to conduct a wide search encompassing studies that examined alternative pathogen models.

\section{Eligibility criteria}

We sought to define and characterise the state of global medical-grade mask shortages that have resulted from the COVID-19 pandemic. In order to be included in the review, records needed to focus on transmission or prevention of SARS and other respiratory illnesses; strategies for extended use, reuse and decontamination of medical-grade masks; or the efficacy and safety of alternative and improvised masks with regard to materials, design and decontamination strategies. Our review was intended to evaluate the evidence pertaining to medicalgrade facial protection currently in use. As a result, we limited our search to records published or most recently updated between 1 January 2000 and 24 March 2020 to ensure that the results would be applicable to current PPE standards. Records were included if they were written in English and described an aspect of COVID-19 transmission prevention or the usage of PPE. Preclinical and quantitative studies were included, in addition to grey literature, in order to consider different aspects of disease transmission and protective equipment.

\section{Information sources and search}

The scope, methodology and timeline of this review were restricted as a result of the pandemic and time-sensitive nature of the information. Peer-reviewed documents were identified using a single database, MEDLINE via PubMed. The full electronic search strategy for PubMed 
and Google is included in online supplementary file 1. Due to the novel nature of the COVID-19 pandemic, the review included grey literature such as preprint publications, product descriptions, guidelines, guidance documents and news articles in addition to peerreviewed publications. We initially used grey literature to define best or recommended practices, then analysed peer-reviewed documents. This diverse array of sources was included with the intention of capturing a more complete picture of the rapidly developing nature of the COVID-19 pandemic, need for medical-grade PPE and global responses. A search of Google with no date restrictions was conducted between 15 March 2020 and 24 March 2020 and the first 20 hits were screened. We also considered additional resources we knew existed or were recommended by colleagues, including an independent reviewer $(n=2)$.

\section{Selection of sources of evidence and quality appraisal}

The identified grey literature was reviewed by at least one author and records were selected if eligibility criteria were met. At least one author reviewed titles initially generated from the PubMed searches, selecting those that were available in English and relevant to one of the components addressed above. The relevant titles were exported and duplicates were excluded. Next, the selected records, including both grey literature and peer-reviewed articles, were reviewed by at least two authors according to the following criteria: (1) the record defined or characterised the state of current PPE shortages; defined or characterised the mode of transmission or prevention of COVID-19; examined evidence for the extended use, reuse and decontamination methods for medical grade masks; or addressed the efficacy and safety of alternative and improvised masks, and (2) the record was available in English. This initial search was further refined to exclude articles that were not applicable to healthcare settings, concerned product design at the industrial level, or focused on PPE other than N95 respirators, surgical masks or face shields (figure 1). Published systematic reviews and meta-analyses were excluded, as meta-analysis was beyond the scope of this scoping review. We resolved disagreements on record selection and data extraction by discussion with other authors as needed. Based on the rapid nature of this review in the setting of a global pandemic, our scoping review required process tailoring. We did not prepare or register a protocol for screening titles and abstracts, and our primary literature search was limited to one database. Formal critical appraisal of the quality of individual sources was not performed, as this was beyond the aim of this scoping review.

\section{Data charting}

Each article was tagged by its focus and data charting was performed by at least one author. Extracted data were shared with all authors and used to synthesise the available evidence.

\section{Synthesis of results}

We grouped the records by topic and setting, and when possible, summarised the study designs, measures used and broad findings. The included records are described in online supplementary file 2, with a description of studies' place of origin, setting, population or product studied, intervention and outcome measures. When a systematic review or meta-analysis was identified, we counted the number of studies included in the review that potentially met our inclusion criteria and noted how many studies had been missed by our search $(n=0)$.

\section{Patient and public involvement}

This research was done without patient involvement. Patients were not invited to comment on the study design and were not consulted to develop patientrelevant outcomes or interpret the results. Patients were not invited to contribute to the writing or editing of this document for readability or accuracy.

\section{RESULTS}

\section{Selection and characteristics of sources of evidence}

We retrieved a total of 5462 articles using the search strategy, of which 269 were accessed in full text, and 48 met the inclusion criteria (figure 1). Of these, 35 were basic research, 9 were clinical research and 4 were secondary research. Additionally, a total of 41 grey literature sources were identified through targeted website searching, and 19 met the inclusion criteria (table 2). In total, 48 of the articles were peer reviewed. The full list of included studies is presented in online supplementary file 2.

\section{Medical-grade facial protection}

Evidence with regard to efficacy of medical-grade facial protection is summarised by setting: laboratory/ controlled, inpatient and outpatient.

\section{Laboratory/controlled settings}

In experimental settings, N95 respirators demonstrate efficient filtration of nanoparticles and bioaerosols. ${ }^{6-9}$ When compared with surgical masks in this setting, N95 respirators provide superior protection against aerosols and viruses similar in size to influenza, especially when combined with eye protection..$^{6810-12}$ In one study, layering of up to five surgical masks improved in vivo filtration efficiency, though fit factor scores using this strategy remain markedly inferior to the minimum required for N95 respirators (13.7 vs 100).${ }^{13}$ Nevertheless, isolated surgical mask material protects against $>95 \%$ of viral aerosols under laboratory conditions, while surgical masks are able to reduce aerosolised influenza exposure by an average of sixfold, depending on mask design. ${ }^{14} 15$

Mask fit is another important component in the functional efficacy of N95 respirators. Untrained individuals without proper fit testing can often achieve Federal Drug Administration (FDA) minimum fit factor standards, but fewer than $25 \%$ achieve the score of 100 expected 

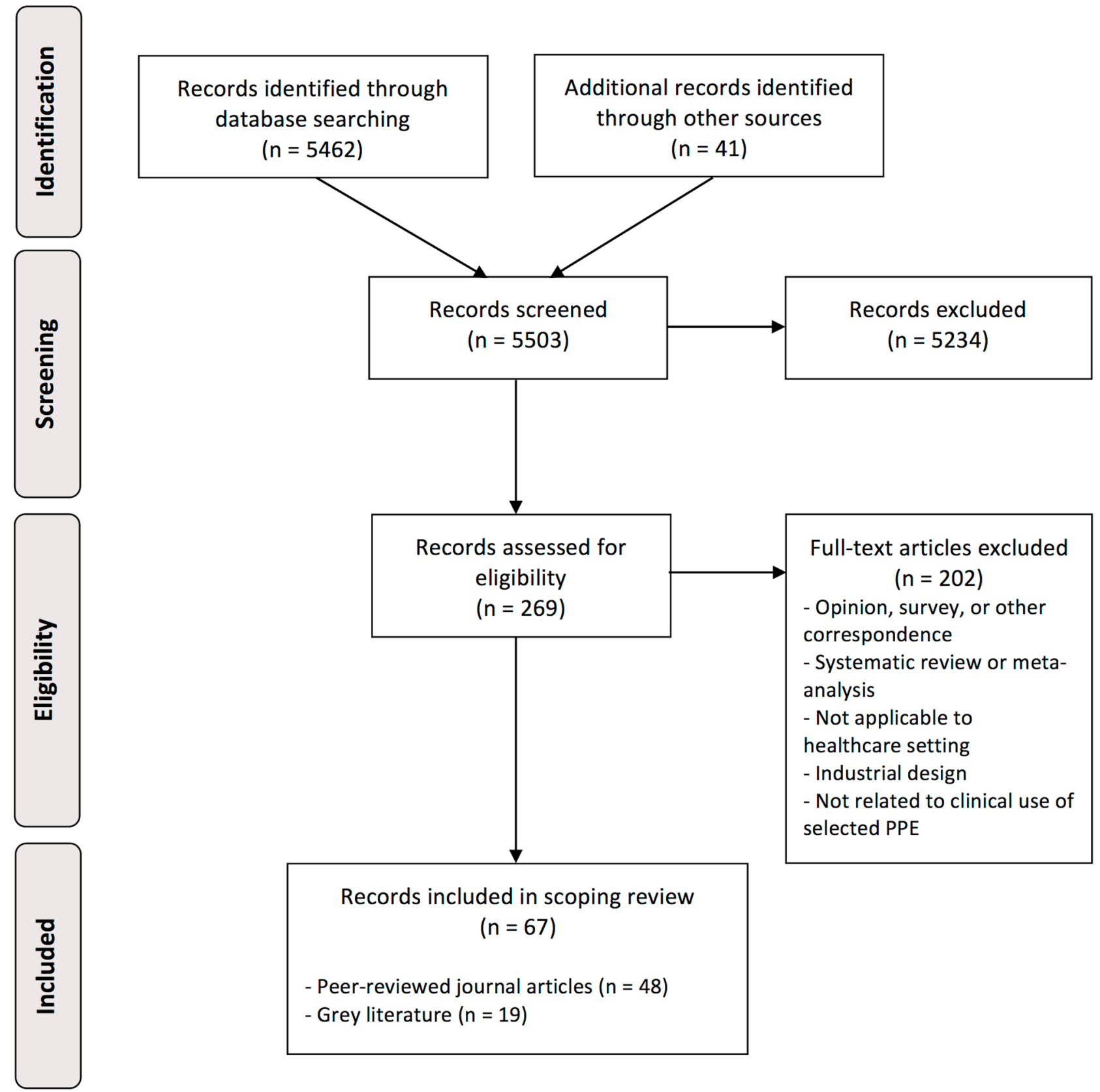

Records included in scoping review

$$
(n=67)
$$

- Peer-reviewed journal articles $(n=48)$

- Grey literature $(n=19)$

Figure 1 Summary of search, selection and inclusion process. PPE, personal protective equipment.

\begin{tabular}{|c|c|c|}
\hline Record type & $\begin{array}{l}\text { Identified } \\
\text { studies, } \mathbf{n}\end{array}$ & $\begin{array}{l}\text { Identified } \\
\text { studies } \\
(\%)\end{array}$ \\
\hline Basic research & 35 & 52.2 \\
\hline Clinical research & 9 & 13.4 \\
\hline $\begin{array}{l}\text { randomised controlled trial } \\
\text { (RCT) }\end{array}$ & 8 & \\
\hline Case series & 1 & \\
\hline Secondary research & 4 & 6.0 \\
\hline Grey literature & 19 & 28.4 \\
\hline Total & 67 & \\
\hline
\end{tabular}

in workplace settings. ${ }^{16}$ Addition of a peripheral Vaseline barrier has been shown to prevent peripheral air leakage and reduce exposure to airborne viral particles, making this a potential compensatory strategy when fit testing is not feasible. ${ }^{17}$ Further evidence regarding mask fit in the inpatient setting is presented in the next section.

The use of face shields as an adjunct to medicalgrade masks has been employed during the COVID-19 pandemic. Face shields provide barrier protection from splash and splatter contamination, as well as acutely expelled aerosols generated during procedures such as bronchoscopy, airway suctioning and intubation. ${ }^{18}$ However, the evidence for the effectiveness of face shields in preventing transmission of viral respiratory diseases is minimal, as highlighted in a recent narrative review. ${ }^{19}$ 
Our scoping review identified only one study that evaluated face shields for respiratory protection. Using cough simulation, researchers demonstrated that face shields were shown to reduce the risk of inhalation exposure up to $95 \%$ immediately following aerosol production. However, protection was decreased with smaller aerosol particles and $30 \mathrm{~min}$ after cough simulation, due to persistence of airborne particles and particle flow around the sides of the mask. ${ }^{20}$ Because they lack a peripheral seal, face shields should not be used as primary protection for preventing respiratory disease transmission, but can be used as an adjunct to other facial protection.

\section{Inpatient settings}

Several studies have been conducted examining the efficacy of medical-grade masks in the inpatient setting. A small randomised controlled trial (RCT) found that incidence of upper respiratory infection symptoms was similar between groups of inpatient healthcare workers who wore surgical masks and those who did not wear masks. ${ }^{21}$ However, studies comparing efficacy of different types of medical-grade masks in the inpatient setting have conflicting results. One non-inferiority RCT of nurses working in medical and paediatric inpatient units found that use of a surgical mask compared with a fit-tested N95 respirator resulted in non-inferior rates of laboratoryconfirmed influenza. ${ }^{22}$ Several other RCTs found that rates of respiratory infection illness were lower in healthcare workers who used fit-tested N95 respirators compared with those who used surgical masks. ${ }^{23-25}$ Similarly, N95 respirators have been shown to provide superior protection against respiratory bacterial infections or bacterial-viral coinfections when compared with surgical masks. ${ }^{26}$ The literature regarding mask fit in the inpatient setting is limited to one study. An RCT comparing fit-tested and non-fit-tested N95 respirators found no significant difference in ability to protect against respiratory illness, despite in vitro evidence of significant reduction in filtration efficacy with peripheral air leakage. ${ }^{24} 27$ Furthermore, non-fit-tested N95 respirators were significantly more protective than surgical masks. ${ }^{24}$ In the context of COVID-19, a recent case report identified 41 healthcare workers exposed to SARS-CoV-2 through aerosol-generating procedures. Among these providers, $85 \%$ were wearing surgical masks at the time of exposure, and the remaining $15 \%$ were wearing N95 respirators. ${ }^{28}$ None of the exposed providers contracted COVID-19. ${ }^{28}$ Our scoping review did not identify any other studies comparing the efficacy of medical-grade masks during aerosol-generating procedures.

Although extended use and reuse of N95 respirators have been suggested as conservation strategies to meet pandemic-level demands, the safety and effectiveness of these practices remain unclear. ${ }^{29}$ These devices maintain function for 8 hours of continuous or intermittent use. ${ }^{30}$ Manufacturers recommend disposal of N95 respirators after close contact with a patient with an infectious disease, after use during an aerosol-generating procedure or on contamination with bodily fluids. ${ }^{30}$ However, extended use in combination with appropriate hand hygiene and contamination-limiting practice is considered minimal risk in the context of typical patient interactions. ${ }^{31}$ In one study, continuous use of N95 respirators by healthcare workers in the inpatient hospital setting was more effective for prevention of respiratory illness than targeted use only during high-risk procedures. ${ }^{23}$ Addition of a cleanable face shield or surgical mask over an N95 respirator has been proposed as a method of extending respirator use, though this approach lacks epidemiological evidence and can exacerbate user discomfort due to increased respiratory resistance. ${ }^{32}$ Although the maximum number of potential reuse cycles before respirator compromise has not been defined, one laboratory study demonstrated a decrease in fit factor below the acceptable limit after five consecutive donnings. ${ }^{33}$

\section{Outpatient settings}

The evidence comparing the efficacy of N95 respirators to surgical masks in the outpatient setting is minimal. One RCT conducted in the outpatient setting found no difference in rates of respiratory illness between healthcare workers who used N95 respirators compared with those who used surgical masks. ${ }^{34}$

\section{N95 respirator decontamination procedures}

Ideal N95 respirator decontamination methods should preserve integrity and filtration properties, appropriately disinfect and not harm the user. ${ }^{35}$ Studies using SARS-CoV-1 models have observed the persistence of infectious particles for up to 24 hours on N95 respirators and suggest that reuse without interim decontamination could result in a compounded viral load. ${ }^{3637}$ A number of trials have evaluated N95 respirator function and stability after various decontamination procedures. Although they may be effective for viral inactivation, methods using microwave irradiation, microwave-generated steam and moist heat incubation can compromise the physical integrity of respirator components. ${ }^{38-41}$ Treatment with bleach results in residual odour, release of chlorine gas on exposure to moisture and, in one model, partial nose pad dissolution without an associated increase in aerosol penetration. ${ }^{38}{ }^{39}$ Decontamination with hydrogen peroxide gas plasma, autoclave, $160^{\circ} \mathrm{C}$ dry heat, $70 \%$ isopropyl alcohol and soaking in soap and water may cause significant loss of filtration efficiency. ${ }^{39} 42$

Although ultraviolet germicidal irradiation (UVGI) has previously been shown to inactivate SARS-CoV-1 and preserve N95 performance after three cycles of exposure (totalling $45 \mathrm{~min}$ at $1.8 \mathrm{~mW} / \mathrm{cm}^{2}$ ), one study found that increasing UVGI doses could compromise the strength of N95 respirator material and straps. ${ }^{39}{ }^{43-45}$ A recent analysis of N95 decontamination methods using Escherichia coli as a surrogate model for SARS-CoV-2 found that application of chlorine and alcohol-based methods led to a significant decrease in the efficiency of N95 filtration media due to loss of microfibre static charge, while 
use of ultraviolet light, boiling water vapour and dry oven heating maintained filtration efficiency and successfully decontaminated N95 respirators. ${ }^{46}$

Overall, strategies involving the use of UVGI, ethylene oxide, dry oven heating and hydrogen peroxide vapour may be most promising for preservation of mask function and integrity. ${ }^{38-40} 42$ Decontamination with UVGI, moist heat incubation and microwave-generated steam does not appear to significantly affect N95 respirator fit or comfort. ${ }^{47}$ Until application of these methods has been adequately investigated in the hospital setting, their safety and effectiveness in the particular context of the SARS-CoV-2 outbreak is unknown. Although decontamination and reuse of N95 respirators could help conserve facial protection during emergency shortages or in lowresource settings, additional research is required to understand the impact of these methods on mask fit and function, as well as their effectiveness against SARS-CoV-2.

\section{Improvised masks}

Previous outbreaks and estimations of PPE shortages sparked a call for further research to assess the effectiveness of improvised masks, but the current evidence is minimal. ${ }^{3548}$ One RCT including inpatient nurses and doctors found incidence of respiratory illness to be significantly higher in healthcare workers with continuous use of two-layer, cotton cloth masks compared with those who wore surgical masks (relative risk $=13.00,95 \%$ CI 1.69 to 100.07). ${ }^{49}$ Particle penetration was approximately $97 \%$ for cloth masks versus $44 \%$ for surgical masks. However, the authors were unable to determine the relative efficacy of cloth masks compared with no mask use since the study lacked a no-mask control arm. ${ }^{49}$

Outside of the inpatient hospital setting, the evidence on the effectiveness of improvised masks is limited to laboratory or controlled settings. ${ }^{50} 51$ One in vitro study analysed the protection that an N95 equivalent, a surgical mask and an improvised tea cloth mask conferred on the wearer and individuals surrounding a simulated infectious patient. ${ }^{50}$ The N95 equivalent respirator provided the best protection, followed by the surgical mask, then the home-made tea cloth mask. Though this study did not have an unmasked control group, cloth masks were found to have a protection factor greater than one, and the authors concluded that cloth masks were superior to no masks for decreasing exposure and infection risk on a population level. ${ }^{50}$ In another study comparing surgical masks and home-made masks crafted from cotton T-shirts, surgical masks were found to be three times as effective for reducing micro-organisms expelled by the wearer, with a fit factor double that of the homemade masks. ${ }^{51}$ However, both masks significantly reduced droplet dispersal.

Cloth masks are a low-cost alternative but appear to provide inferior protection against respiratory illnesses for several possible reasons. Because cloth masks can retain moisture, be reused and require cleaning, they may increase the infection risk for hospital care workers. ${ }^{49}$ The number of layers may also contribute to the mask's ability to prevent viral transmission. Cloth masks usually have one to two layers of protection compared with the fourlayered N95 respirator. ${ }^{52}$ Similar to medical-grade masks, fit is an important factor in the effectiveness of improvised masks. ${ }^{27}{ }^{52-54}$ Peripheral air leakage can expose the wearer to airborne viral particles. Studies have shown that air leakage from an improvised mask can be reduced when the discussed materials are used in combination with additional measures to improve facial fit (e.g., nylon hosiery). ${ }^{35}$

Although household fabrics are not intended for respiratory protection, these materials may still have limited capacity for small-particle filtration. ${ }^{48}$ An in vitro study found that a sweatshirt made of $70 \%$ cotton $/ 30 \%$ polyester had the greatest resistance to penetration by various uniform and non-uniform nanosized particles compared with other household materials. Researchers also found that the particle filtration performance of certain cotton and polyester household fabrics may compare to some surgical masks. ${ }^{455}$ However, this study did not evaluate the effectiveness of these fabrics for protecting against droplets or liquids and overall concluded that filtration efficiency varied greatly by fabric. ${ }^{48}$

Other investigators found that tea towels and a cottonblend fabric captured $0.02 \mu \mathrm{m}$ particles with respective effectiveness of $73 \%$ and $70 \%$, while the scarves tested were shown to be less than $50 \%$ effective. ${ }^{51}$ In the same study, vacuum cleaner bags were shown to be $89 \%$ effective in capturing $0.02 \mu \mathrm{m}$-sized particles, but were not recommended due to their poor breathability. ${ }^{51}$ Based on filtration efficacy and breathability, the authors concluded that pillowcases and $100 \%$ cotton T-shirts were the best readily available household options for improvised masks, with the T-shirt preferred due to its potential for superior fit. ${ }^{51}$ This inconclusive evidence for the best choice of material may be partially explained by the heterogeneity of factors in fabric construction, including fibre density and the influence of tensile strength, air permeability and flexural rigidity of the fabric. ${ }^{35}$ Improvised mask design is another variable of unknown significance. For example, in one study, a cloth mask with an exhaust valve and a conical tetrahedral shape outperformed the filtration ability of other cloth masks with most particle sizes. Unfortunately, the material composition of each cloth mask was unknown. ${ }^{56}$

The use of surgical sterilisation wrap has been proposed as medical and community groups organise to make improvised masks in light of facial protection shortages. ${ }^{57}$ This material is a component of surgical instrument packaging used to maintain sterility. Some surgical wraps are made using a spunbond/meltblown/spunbond nonwoven polypropylene fabric, which may be similar to the non-woven, meltblown fabric used in medical-grade masks. ${ }^{58-60}$ Sterilisation wrap is also made to meet FDA standards of bacterial filtration efficiency (BFE), a test performed on materials designed to protect against aerosols, and some report a BFE of $98.9 \%-99.9 \%$. ${ }^{61-63}$ 
Surgical sterilisation wrap is widely used and readily accessible in many healthcare settings. However, we could find no evidence on the applicability of sterilisation wrap for masks or data on their protection against respiratory viruses. Use of sterilisation wrap as material for improvised masks or as filter insert in cloth masks should take this lack of evidence into account.

\section{Addition of layers/filters}

As previously discussed, adding layers to a cloth mask could theoretically increase its effectiveness. However, there are little to no data available regarding effectiveness of a two-layer cloth mask with a middle filter and only one study that may guide the choice of said filter. Even with this scarcity of evidence, some may choose to add a filter to improve the effectiveness of an improvised cloth mask. When considering incorporation of a filter material, it is important to consider durability, breathability and the need for replacement. ${ }^{51}$ Recently, some have proposed using heating, ventilation and airconditioner filter inserts with particle size filtration properties similar to those of $\mathrm{N} 95$ respirators. ${ }^{64}$ Electrostatic cotton and non-woven, meltblown fabric are both known components of medical-grade masks and may also serve as useful filters. However, availability, access and costs of these materials are likely to be prohibitive. ${ }^{65}$ Of note, a news report from South Korea mentions an innovative washable electrostatic cotton which can serve as a more durable, insertable filter ${ }^{66}$ Further research is needed to assess the effectiveness and safety of these materials for preventing respiratory infection and penetration of viral particles. This information may be particularly useful in low-resource settings if effective materials are inexpensive and readily accessible.

\section{Reuse and decontamination of improvised masks}

While guidance for handling contaminated laundry in households with suspected or confirmed COVID-19 cases exists, our scoping review did not identify any literature regarding reuse and decontamination of improvised masks. If improvised masks with filters are made, our scoping review again found no evidence regarding their appropriate use and decontamination. However, it may be reasonable to treat the insertable filter as a single-use material and frequent change should be considered.

\section{DISCUSSION}

Evidence supports the superiority of medical-grade masks for protection against respiratory viruses. In cases when medical-grade masks are not available, the summarised research indicates that protection offered by certain improvised or reused masks is better than no protection at all. ${ }^{50}$ Improvised masks may be helpful in emergency situations, supply shortages, low-resource settings or for citizens in low-risk environments in order to preserve medical-grade facial protection for healthcare workers. However, there is a lack of evidence regarding optimal improvised mask design and material, and whether combination with a face shield enhances protection.

Scientific research on SARS-CoV-2 is rapidly progressing and more information about proper PPE, improvised facial protection and effective decontamination methods may be forthcoming. There are many opportunities for future research in this field. Additional evidence regarding the safety and effectiveness of alternative facial protection is required in order to better equip individuals to make improvised facial protection when necessary. Specifically, further research on the effectiveness of an improvised cloth mask with an added filter versus cloth alone is warranted. In addition, comparisons of different possible filter media are warranted and should include discussion about accessibility of materials and the creation of guidelines for reuse. Finally, development of effective and safe decontamination methods that do not compromise the integrity or filtration properties of facial protection is needed.

This review has several limitations. The literature included in this review is limited in scope, design, sample size and population diversity. Articles written in languages other than English were excluded, which particularly limited the evaluation of recent articles related to the COVID-19 pandemic. Studies on SARS-CoV-2 have been performed in settings experiencing the early phases of the pandemic, which does not lend easily to standardised RCTs or uniform study planning and execution. Additionally, studies performed prior to the COVID-19 outbreak were not specific to SARS-CoV-2, and it is unknown whether those results are applicable in the current context. Our review also included a number of small RCTs and observational studies, which have less statistical power, as well as non-peer-reviewed articles.

\section{CONCLUSIONS}

The COVID-19 pandemic has led to a massive medical PPE shortage. Alternative forms of facial protection are less effective, but may serve as an intermediary in emergent situations. Based on the literature, the safest approach to address this shortage is to ensure provision of a sufficient quantity of medical-grade facial protection for healthcare workers. Considering the limited evidence, reused and improvised masks should be used as a last resort, but may be beneficial when medical-grade facial protection is unavailable. Face shields should not be used as primary protection, but rather as an adjunct to improvised masks. Public health and medical institutions should be prepared to ensure the safety of healthcare workers in all stages of crises. Therefore, it is necessary to continue research and the publication of evidence-based emergency protocols that include recommendations for improvised protection.

Twitter Laura R Garcia Godoy @LauraRGarciaG, Amy E Jones @AmyJonesPDX, Taylor N Anderson @tayloander, Kylie M L Seeley @kylie_seeley, Erynn A Beeson @erynnbeeson, Jaime W Peterson @jaimewildman and Peter D Sullivan @PeteSullivanPDx 
Acknowledgements The authors extend thanks to the following individuals for their contributions to this work: Jeffery S Loutit, MBChB; Margarita M Aulet-Leon, BA; Lubna Khan, BS; Evan J Barnes, MS; Sarah C Newhall, BA; Jessica A Blank, BS; Leah C Snyder, BS; Mollie C Marr, BFA.

Contributors All authors contributed to the concept design and scope of this review. LRGG and AEJ wrote the first draft of the review. CLF, TNA, KMLS, HKZ and EAB equally contributed individual sections and additional writing. PDS and JWP reviewed and edited the paper and provided clinical insight and thematic guidance. All authors reviewed, edited and approved the final manuscript.

Funding The authors have not declared a specific grant for this research from any funding agency in the public, commercial or not-for-profit sectors.

Competing interests None declared.

Patient and public involvement Patients and/or the public were not involved in the design, or conduct, or reporting, or dissemination plans of this research.

Patient consent for publication Not required.

Provenance and peer review Commissioned; internally peer reviewed.

Data availability statement There are no data in this work.

Open access This is an open access article distributed in accordance with the Creative Commons Attribution Non Commercial (CC BY-NC 4.0) license, which permits others to distribute, remix, adapt, build upon this work non-commercially, and license their derivative works on different terms, provided the original work is properly cited, appropriate credit is given, any changes made indicated, and the use is non-commercial. See: http://creativecommons.org/licenses/by-nc/4.0/.

\section{ORCID iDs}

Laura R Garcia Godoy http://orcid.org/0000-0003-2215-6463

Amy E Jones http://orcid.org/0000-0001-6122-9317

Taylor N Anderson http://orcid.org/0000-0002-8608-8343

Cameron L Fisher http://orcid.org/0000-0002-3130-7625

Kylie M L Seeley http://orcid.org/0000-0002-0363-6069

Erynn A Beeson http://orcid.org/0000-0002-8936-3996

Hannah K Zane http://orcid.org/0000-0002-2045-7062

Jaime W Peterson http://orcid.org/0000-0001-9990-7128

Peter D Sullivan http://orcid.org/0000-0001-6567-4135

\section{REFERENCES}

1 World Health Organization. Novel Coronavirus (2019-nCoV) situation reports [Internet]. Available: https://www.who.int/emergencies/ diseases/novel-coronavirus-2019/situation-reports [Accessed 23 Mar 2020].

2 WHO Director. General's opening remarks at the media briefing on 2019 novel coronavirus, 2020. Available: https://www.who.int/ $\mathrm{dg} /$ speeches/detail/who-director-general-s-opening-remarks-atthe-media-briefing-on-2019-novel-coronavirus-7-february-2020 [Accessed 23 Mar 2020].

3 Padilla M. 'It Feels Like a War Zone': Doctors and Nurses Plead for Masks on Social Media. The New York Times [Internet], 2020. Available: https://www.nytimes.com/2020/03/19/us/hospitalscoronavirus-ppe-shortage.html [Accessed 23 Mar 2020].

4 World Health Organization. Rational use of personal protective equipment (PPE) for coronavirus disease (COVID-19): interim guidance, 19 March 2020. Institutional Repos Inf Shar 2020:7.

5 Tricco AC, Lillie E, Zarin W, et al. PRISMA extension for scoping reviews (PRISMA-ScR): checklist and explanation. Ann Intern Med 2018;169:467.

6 Elmashae RBY, Grinshpun SA, Reponen T, et al. Performance of two respiratory protective devices used by home-attending health care workers (a pilot study). J Occup Environ Hyg 2017;14:D145-9.

7 Jeong SB, Ko HS, Seo SC, et al. Evaluation of filtration characteristics and microbial recovery rates of commercial filtering facepiece respirators against airborne bacterial particles. Sci Total Environ 2019;682:729-36.

8 Lindsley WG, King WP, Thewlis RE, et al. Dispersion and exposure to a cough-generated aerosol in a simulated medical examination room. J Occup Environ Hyg 2012;9:681-90.

9 Harnish DA, Heimbuch BK, Husband M, et al. Challenge of N95 filtering facepiece respirators with viable $\mathrm{H} 1 \mathrm{~N} 1$ influenza aerosols. Infect Control Hosp Epidemiol 2013;34:494-9.

10 Lee S-A, Grinshpun SA, Reponen T. Respiratory performance offered by N95 respirators and surgical masks: human subject evaluation with $\mathrm{NaCl}$ aerosol representing bacterial and viral particle size range. Ann Occup Hyg 2008;52:177-85.

11 Bałazy A, Toivola M, Adhikari A, et al. Do N95 respirators provide 95\% protection level against airborne viruses, and how adequate are surgical masks? Am J Infect Control 2006;34:51-7.

12 Bischoff WE, Reid T, Russell GB, et al. Transocular entry of seasonal influenza-attenuated virus aerosols and the efficacy of n95 respirators, surgical masks, and eye protection in humans. $J$ Infect Dis 2011;204:193-9.

13 Derrick JL, Gomersall CD. Protecting healthcare staff from severe acute respiratory syndrome: filtration capacity of multiple surgical masks. J Hosp Infect 2005;59:365-8.

14 Wen Z, Yu L, Yang W, et al. Assessment the protection performance of different level personal respiratory protection masks against viral aerosol. Aerobiologia 2013;29:365-72.

15 Makison Booth C, Clayton M, Crook B, et al. Effectiveness of surgical masks against influenza bioaerosols. J Hosp Infect 2013;84:22-6.

16 Brosseau LM. Fit testing respirators for public health medical emergencies. J Occup Environ Hyg 2010;7:628-32.

17 Patel RB, Skaria SD, Mansour MM, et al. Respiratory source control using a surgical mask: an in vitro study. J Occup Environ Hyg 2016;13:569-76.

18 Bunyan D, Ritchie L, Jenkins D, et al. Respiratory and facial protection: a critical review of recent literature. $J$ Hosp Infect 2013;85:165-9.

19 Roberge RJ. Face shields for infection control: a review. J Occup Environ Hyg 2016;13:235-42.

20 Lindsley WG, Noti JD, Blachere FM, et al. Efficacy of face shields against cough aerosol droplets from a cough simulator. $J$ Occup Environ Hyg 2014;11:509-18.

21 Jacobs JL, Ohde S, Takahashi O, et al. Use of surgical face masks to reduce the incidence of the common cold among health care workers in Japan: a randomized controlled trial. Am J Infect Control 2009;37:417-9.

22 Loeb M, Dafoe N, Mahony J, et al. Surgical mask vs N95 respirator for preventing influenza among health care workers: a randomized trial. JAMA 2009;302:1865-71.

23 Maclntyre CR, Chughtai AA, Rahman B, et al. The efficacy of medical masks and respirators against respiratory infection in healthcare workers. Influenza Other Respir Viruses 2017:11:511-7.

24 Maclntyre CR, Wang Q, Cauchemez S, et al. A cluster randomized clinical trial comparing fit-tested and non-fit-tested N95 respirators to medical masks to prevent respiratory virus infection in health care workers. Influenza Other Respir Viruses 2011;5:170-9.

25 Maclntyre $\mathrm{CR}$, Wang Q, Seale $\mathrm{H}$, et al. A randomized clinical trial of three options for N95 respirators and medical masks in health workers. Am J Respir Crit Care Med 2013;187:960-6.

26 Maclntyre CR, Wang Q, Rahman B, et al. Efficacy of face masks and respirators in preventing upper respiratory tract bacterial colonization and co-infection in hospital healthcare workers. Prev Med 2014:62:1-7.

27 Rengasamy S, Eimer BC. Total inward leakage of nanoparticles through filtering facepiece respirators. Ann Occup Hyg 2011;55:253-63.

$28 \mathrm{Ng} \mathrm{K}$, Poon BH, Kiat Puar TH, et al. COVID-19 and the risk to health care workers: a case report. Ann Intern Med 2020.

29 Carias C, Rainisch G, Shankar M, et al. Potential demand for respirators and surgical masks during a hypothetical influenza pandemic in the United States. Clin Infect Dis 2015;60:S42-51.

30 National Institute for Occupational Safety and Health. CDC Recommended Guidance for Extended Use and Limited Reuse of N95 Filtering Facepiece Respirators in Healthcare Settings NIOSH Workplace Safety and Health Topic [Internet]. Pandemic Planning, 2020. Available: https://www.cdc.gov/niosh/topics/ hcwcontrols/recommendedguidanceextuse.html [Accessed 24 Mar 2020].

31 Fisher EM, Shaffer RE. Considerations for recommending extended use and limited reuse of filtering facepiece respirators in health care settings. J Occup Environ Hyg 2014;11:D115-28.

32 Roberge RJ. Effect of surgical masks worn concurrently over N95 filtering facepiece respirators: extended service life versus increased user burden. J Public Health Manag Pract 2008;14:E19-26.

33 Bergman MS, Viscusi DJ, Zhuang Z, et al. Impact of multiple consecutive donnings on filtering facepiece respirator fit. Am J Infect Control 2012;40:375-80.

34 Radonovich LJ, Simberkoff MS, Bessesen MT, et al. N95 respirators vs medical masks for preventing influenza among health care personnel: a randomized clinical trial. JAMA 2019;322:824-33.

35 Institute of Medicine. Reusability of Facemasks During an Influenza Pandemic: Facing the Flu [Internet], 2006. Available: https://www. 
nap.edu/catalog/11637/reusability-of-facemasks-during-aninfluenza-pandemic-facing-the-flu [Accessed 23 Mar 2020].

36 Casanova LM, Waka B. Survival of a surrogate virus on N95 respirator material. Infect Control Hosp Epidemiol 2013;34:1334-5.

37 Casanova L, Rutala WA, Weber DJ, et al. Coronavirus survival on healthcare personal protective equipment. Infect Control Hosp Epidemiol 2010;31:560-1.

38 Viscusi DJ, Bergman MS, Eimer BC, et al. Evaluation of five decontamination methods for filtering facepiece respirators. Ann Occup Hyg 2009;53:815-27.

39 Bergman MS, Viscusi DJ, Heimbuch BK, et al. Evaluation of multiple (3-Cycle) decontamination processing for filtering Facepiece respirators. J Eng Fibers Fabr 2010;5:155892501000500400.

40 Lore MB, Heimbuch BK, Brown TL, et al. Effectiveness of three decontamination treatments against influenza virus applied to filtering facepiece respirators. Ann Occup Hyg 2012;56:92-101.

41 Fisher EM, Williams JL, Shaffer RE. Evaluation of microwave steam bags for the decontamination of filtering facepiece respirators. PloS One 2011;6:e18585.

42 Viscusi DJ, King WP, Shaffer RE. Effect of decontamination on the filtration efficiency of two filtering Facepiece respirator models. $J$ Int Soc Respir Prot 2007;24:15.

43 Darnell MER, Subbarao K, Feinstone SM, et al. Inactivation of the coronavirus that induces severe acute respiratory syndrome, SARSCoV. J Virol Methods 2004;121:85-91.

44 Duan S-M, Zhao X-S, Wen R-F, et al. Stability of SARS coronavirus in human specimens and environment and its sensitivity to heating and UV irradiation. Biomed Environ Sci 2003;16:246-55

45 Lindsley WG, Martin SB, Thewlis RE, et al. Effects of ultraviolet germicidal irradiation (UVGI) on N95 respirator filtration performance and structural integrity. J Occup Environ Hyg 2015;12:509-17.

46 Price A, Chu L, Learnly COVID-19 Evidence Service. Addressing COVID-19 Face Mask Shortages [v1.1] [Internet], 2020. Available: https://stanfordmedicine.app.box.com/v/covid19-PPE-1-1 [Accessed 24 Mar 2020].

47 Viscusi DJ, Bergman MS, Novak DA, et al. Impact of three biological decontamination methods on filtering facepiece respirator fit, odor, comfort, and donning ease. J Occup Environ Hyg 2011;8:426-36.

48 Rengasamy S, Eimer B, Shaffer RE. Simple respiratory ProtectionEvaluation of the filtration performance of cloth masks and common fabric materials against $20-1000 \mathrm{~nm}$ size particles. Ann Occup Hyg 2010;54:789-98.

49 Maclntyre CR, Seale H, Dung TC, et al. A cluster randomised trial of cloth masks compared with medical masks in healthcare workers. BMJ Open 2015:5:e006577.

50 van der Sande M, Teunis P, Sabel R. Professional and home-made face masks reduce exposure to respiratory infections among the general population. PLoS One 2008;3:e2618. [Internet].

51 Davies A, Thompson K-A, Giri K, et al. Testing the efficacy of homemade masks: would they protect in an influenza pandemic? Disaster Med Public Health Prep 2013;7:413-8.

52 Dato VM, Hostler D, Hahn ME, et al. Emerg Infect Dis 2006:12:1033-4

53 Brochot C, Michielsen N, Chazelet S, et al. Measurement of protection factor of respiratory protective devices toward nanoparticles. Ann Occup Hyg 2012;56:595-605.
54 Reponen T, Lee S-A, Grinshpun SA, et al. Effect of fit testing on the protection offered by $n 95$ filtering facepiece respirators against fine particles in a laboratory setting. Ann Occup Hyg 2011;55:264-71.

55 Oberg T, Brosseau LM. Surgical mask filter and fit performance. Am J Infect Control 2008;36:276-82.

56 Shakya KM, Noyes A, Kallin R, et al. Evaluating the efficacy of cloth facemasks in reducing particulate matter exposure. J Expo Sci Environ Epidemiol 2017;27:352-7.

57 Providence. 100 Million Masks [Internet]. Available: https://www. providence.org//p/100m-masks [Accessed 24 Mar 2020].

58 Halyard Health. Sequential Sterilization Wrap [Internet]. Available: https://products.halyardhealth.com/surgical-solutions/sterilizationsolutions/sterilization-wraps/halyard-sequential-sterilization-wrap. html [Accessed 24 Mar 2020].

59 Rutala WA, Weber DJ. Choosing a Sterilization Wrap for SurgicalPacks [Internet]. Infection Control Today, 2000. Available: https://www.infectioncontroltoday.com/environmental-hygiene/ choosing-sterilization-wrap-surgicalpacks [Accessed 24 Mar 2020].

60 Filligent (HK) limited. BioFriend BioMask N95 surgical respirator, model: professional BF-200-3013AN. Sheung Wan 2013.

61 Centers for Disease Control and Prevention. NIOSH Personal Protective Equipment Information [Internet]. Available: https://wwwn. cdc.gov/PPEInfo/Standards/Info/ASTMF210114 [Accessed 24 Mar 2020].

62 Nelson Laboratories, Inc. Bacterial Filtration Efficiency: KIMGUARD ONE-STEP* Sterilization Wrap Compared to Medline Gemini Sterilization Wrap [Internet]. Kimberly-Clark, 2007. Available: https:// www.halyardhealth.in/media/287706/h0486 0701 medlinevskc.pdf [Accessed 21 Mar 2020].

63 Kimberly-Clark Professional. Kimberly-Clark* KC200 Kimguard ${ }^{*}$ Sterilization Wrap [Internet]. Available: https://www.kcprofessional. com/en-us/products/scientific/protective-clothing/68018 [Accessed 24 Mar 2020].

64 National Air Filtration Association. Understanding MERV [Internet]. NAFA User's Guide to ANSI/ASHRAE 52.2, 2018. Available: https:// www.nafahq.org/understanding-merv-nafa-users-guide-to-ansiashrae-52-2/ [Accessed 23 Mar 2020].

65 Feng E, Cheng A. COVID-19 Has Caused A Shortage Of Face Masks. But They're Surprisingly Hard To Make [Internet]. NPR.org. Available: https://www.npr.org/sections/goatsandsoda/2020/03/16/ 814929294/covid-19-has-caused-a-shortage-of-face-masks-buttheyre-surprisingly-hard-to-mak [Accessed 23 Mar 2020].

66 Jung J. Researchers Develop Highly Reusable Mask Filter [Internet]. KAIST, 2020. Available: https://www.koreatechtoday.com/kaistresearchers-develop-highly-reusable-mask-filter/ [Accessed 23 Mar 2020].

67 Center for Devices and Radiological Health. N95 Respirators and Surgical Masks (Face Masks). FDA [Internet], 2020. Available: http:// www.fda.gov/medical-devices/personal-protective-equipmentinfection-control/n95-respirators-and-surgical-masks-face-masks [Accessed 23 Mar 2020].

68 Siegel JD, Rhinehart E, Jackson M, et al. 2007 guideline for isolation precautions: preventing transmission of infectious agents in health care settings. Am J Infect Control 2007;35:S65-164. 